\title{
COVID-19 associated mucormycosis: evolving technologies for early and rapid diagnosis
}

\author{
Rachel Samson ${ }^{1,2} \cdot$ Mahesh Dharne ${ }^{1,2}$ (1)
}

Received: 9 September 2021 / Accepted: 26 November 2021 / Published online: 6 December 2021

(c) King Abdulaziz City for Science and Technology 2021

\begin{abstract}
The post-coronavirus disease (COVID-19) mucormycosis is a deadly addition to the pandemic spectrum. Although it's a rare, aggressive, and opportunistic disease, the associated morbidity and mortality are significant. The complex interplay of factors aggravating CAM is uncontrolled diabetes, irrational and excessive use of antibiotics, steroids, and an impaired immune system. Recently, India has been witnessing a rapid surge in the cases of coronavirus disease-associated mucormycosis (CAM), since the second wave of COVID-19. The devastating and lethal implications of CAM had now become a matter of global attention. A delayed diagnosis is often associated with a poor prognosis. Therefore, the rapid and early diagnosis of infection would be life-saving. Prevention and effective management of mucormycosis depend upon its early and accurate diagnosis followed by a multimodal therapeutic approach. The current review summarizes an array of detection methods and highlights certain evolving technologies for early and rapid diagnosis of CAM. Furthermore, several potential management strategies have also been discussed, which would aid in tackling the neglected yet fatal crisis of mucormycosis associated with COVID-19.
\end{abstract}

Keywords Mucormycosis · COVID-19 · Diagnostics $\cdot$ Biosensors $\cdot$ Probiotics

\section{Introduction}

COVID-19 topples down the immune system and the fungal infections reap its benefit. Since 2019, the pandemic of severe acute respiratory syndrome coronavirus-2 (SARS$\mathrm{CoV}-2$ ) has caused global havoc. Viral respiratory tract infections are usually accompanied by invasive fungal infections (mycoses) that are largely unrecognized but have a significant mortality rate of more than 50\% (Raut and Huy 2021). Recently, critically ill patients with coronavirus disease-19 (COVID-19) were reported vulnerable to secondary infections by bacteria and fungi (Rawson et al. 2021). However, the emerging cases among COVID-19 patients have presented invasive fungal infections, mainly by species of

Mahesh Dharne

ms.dharne@ncl.res.in

1 Academy of Scientific and Innovative Research (AcSIR), Ghaziabad, India

2 Biochemical Sciences Division, National Collection of Industrial Microorganisms (NCIM), CSIR-National Chemical Laboratory, Homi Bhabha Road, Pashan, Pune 411008, Maharashtra, India
Aspergillus, Candida, Rhizopus, Cryptococcus, and Pneumocystis, causing severe complications in the disease outcome (Hoenigl 2020). Being a new virus, the pathogenicity and associated immunological responses with SARS-CoV-2 are incompletely understood. However, the invasion of this virus triggers the release of danger-associated molecular patterns (DAMPs), that are fundamental in the pathogenesis of fungal diseases (Tolle and Standiford 2013). Besides, immune impairment of COVID-19 affected patients due to treatment with broad-spectrum antibiotics, invasive or noninvasive ventilation, immunosuppressive/corticosteroid, establish a favorable niche for the opportunistic infections by fungal pathogens (Segrelles-Calvo et al. 2020). These invasive fungal infections are notoriously challenging, progressive, and have fatal consequences upon delay in their diagnosis or treatment.

Mucormycosis is a rare but serious fungal infection of the skin, sinuses, lungs, and brain, caused by a group of ubiquitously present molds called mucormycetes. Although its occurrence is sporadic, the manifestation can be life-threatening under several medical conditions and the associated risk factors (Cornely et al. 2019). The major fungi associated with mucormycosis at the global scale are Rhizopus 
arrhizus, $R$. microsporous, $R$. homothallicus, Mucor spp. Lichtheimia spp., and Apophysomyces spp. (Prakash and Chakrabarti 2021). Mucormycosis is characterized by vessel thrombosis and subsequent tissue necrosis due to extensive angioinvasion by the fungal hyphae (Spellberg et al. 2005). Apart from aspergillosis and candidiasis being reported as the major fungal superinfections with SARS-CoV-2, a recent upsurge of cases with COVID-associated mucormycosis (CAM) has been reported worldwide at an alarming rate (Singh et al. 2021). Although COVID-19 is a global peril, CAM is more rampant in India. A recent review by John et al., has summarized reported cases of patients with CAM. It was observed that more than $71 \%$ of the cases were from India, and over $94 \%$ of patients had uncontrolled diabetes mellitus (DM) as an underlying condition (John et al. 2021). Typically, during the second wave of COVID-19 infection by the B.1.617.2 (Delta) variant, a sudden increase in the cases of CAM has devastated the prognosis, making it an epidemic in several states (DH Webdesk 2021; Raut and Huy 2021). India is the world capital of diabetes, with around 70 million people with DM (Pandey and Sharma 2018) and a COVID19 caseload of over 31 million (Mallapaty 2021; The Lancet 2021), answers its prevalence in India. On the contrary, patients with hematological malignancies (HM), solid-organ transplantations are most susceptible to mucormycosis in developed countries (Jeong et al. 2019; Reid et al. 2020). Other predisposing factors associated with CAM are chronic kidney disease, steroid/antibiotic therapy, pulmonary tuberculosis, and chronic obstructive pulmonary disease (Prakash and Chakrabarti 2021; Patel et al. 2021). The precise mechanisms of CAM are yet to be elucidated. Meanwhile, rapid detection of the CAM followed by an appropriate line of treatment has become the need of the hour. To address this issue, the current review provides a comprehensive background on CAM, existing and emerging diagnostic/detection methods, and various management strategies to efficiently tackle mucormycosis.

\section{Pathogenesis of mucormycosis and CAM}

\section{A: patho-mechanism of mucormycosis in healthy individuals}

The pathogenesis of mucormycosis, typically by species of Rhizopus involves the entry of fungal spores in the susceptible host through inhalation, ingestion of food-soiled with spores, and through an abraded skin (Baldin and Ibrahim 2017). A spore cot protein cotH is present exclusively in all Mucorales and plays crucial role pathogenesis of mucormycosis. Following the entry, the attachment of fungal spore coat protein $\mathrm{CotH} 3$ to glucose-regulated protein 78 (GRP78) on the surface of endothelial cells occurs (Gebremariam et al. 2019). Upon contact of CotH to the epithelial cells of humans, increased signaling of platelet-derived growth factor receptor B (PDGFRB) occurs which result in subsequent damage of the epithelial cells. The increased PDGFRB provide suitable growth factors for successful germination, development, and growth of Mucorales hyphae. Further, CotH3 plays an important role as invasins and mediate disruption and damage of immune cells, thereby promoting infection (Gebremariam et al. 2014). The mature hyphae produces Mucorales specific $\mathrm{T}$ cells, that in turn produce pro-inflammatory cytokines such as interleukins (IL-4, IL-10 and IL-17) and interferon gamma (IFN- $\gamma$ ) which then stimulate $\mathrm{CD} 4^{+} \mathrm{T}$ cells and cause further damage the host cells. Further, the mature fungal hyphae suppress the release of immunomodulatory molecules such as regulated upon activation, normal T-cell expressed and secreted (RANTES), and IFN- $\gamma$ from the natural killer (NK) cells (Schmidt et al. 2013, 2016). Once the fungal hyphae has invaded the immune system, it intrudes into deep tissues, causing tissue infarction, necrosis, and thrombosis (Brunke et al. 2016). Clinical conditions such as hyperglycemia, diabetes mellitus (DM), and diabetic ketoacidosis (DKA) enhance the expression of GRP78 and CotH3, increasing the susceptibility of the host to mucormycosis (Hassan and Voigt 2019). As the amount of free serum iron is abundant in these individuals, it creates a favorable niche for the growth of Mucorales. These fungi employ their high affinity iron permease to transport and use the available iron for their growth and development inside the human body (Artis et al. 1982; Roilides et al. 2012). Besides, reduced chemotactic factors in DM, DKA, and hyperglycemia conditions, damage the neutrophils, making it facile for the rapid spread of mucormycosis. Details of mucormycosis causing Mucorales, their virulence factors and clinical manifestations have been summarized in Table 1.

\section{B: COVID-19 and mucormycosis: an intertwined association}

The spread of SARS-CoV-2 occurs mainly through droplets, and is characterized by the binding of the virion particle to the angiotensin-converting enzyme 2 (ACE2) receptors of humans, via its spike protein. The infection with SARS-CoV-2 negatively influences the inflammatory response resulting into an uncontrolled immune response, called the cytokine storm. Further, the cellmediated immune response by the CD $4+$ and CD $8+$ T-cells, decreases in COVID-19 patients. Moreover, SARS-COV-2 mediated pneumonia results into atelectasis, which results into COVID-19 associated silent hypoxia. Under normal conditions, the hypoxia-inducible factor or HIF-1 remain inactive. However, during hypoxic conditions of COVID-19, the HIF- $1 \alpha$ transcription factor 


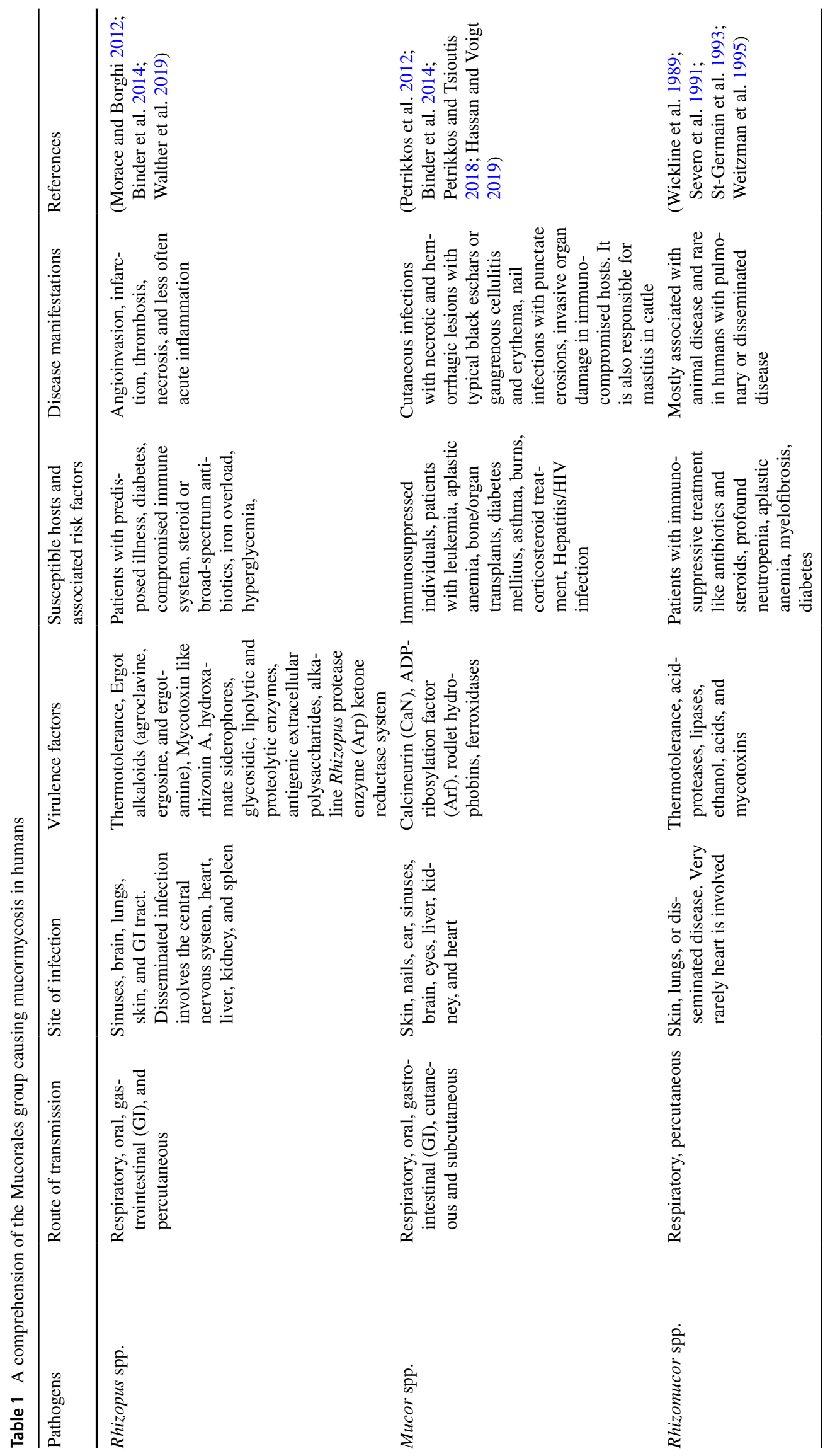




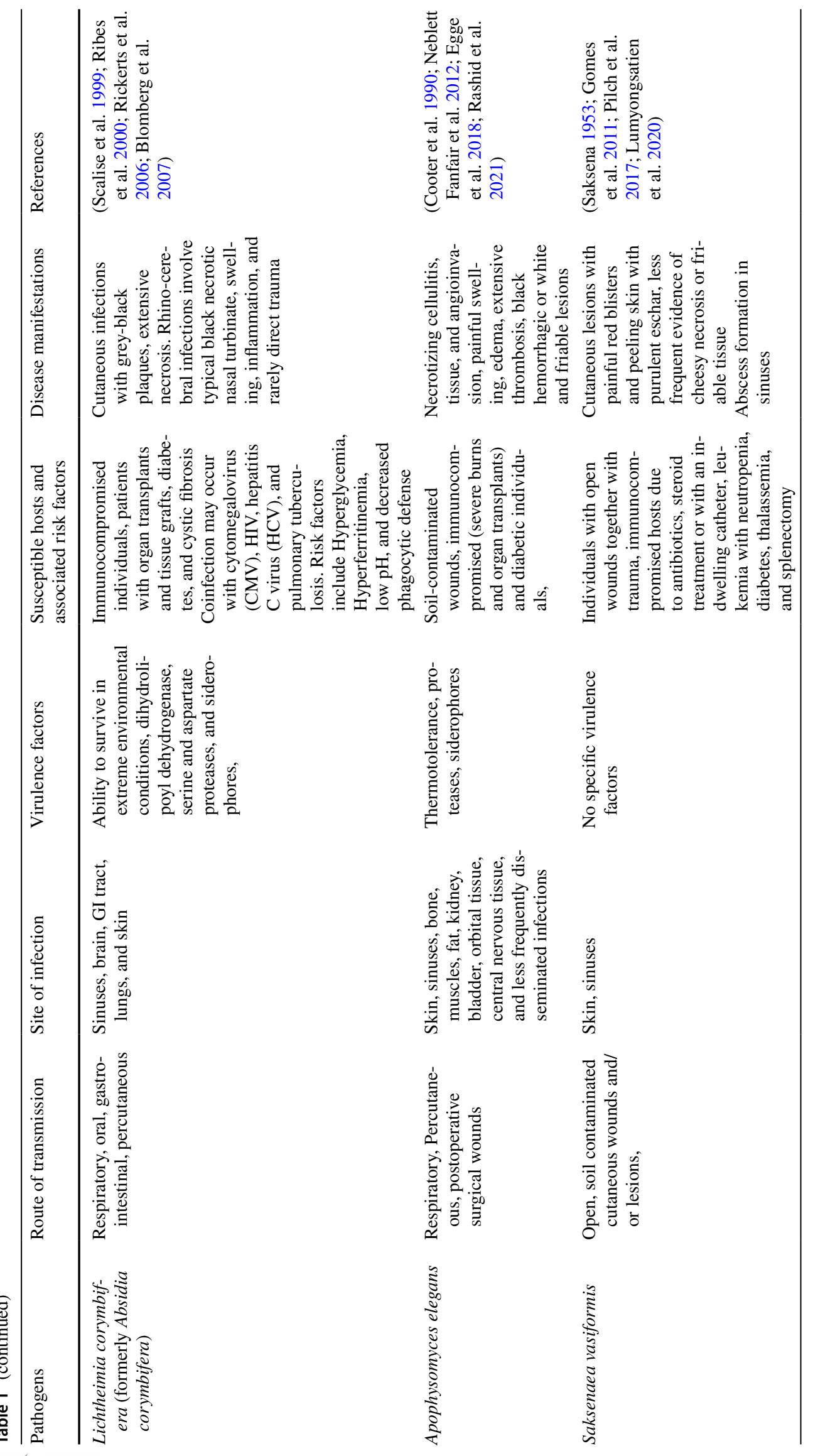




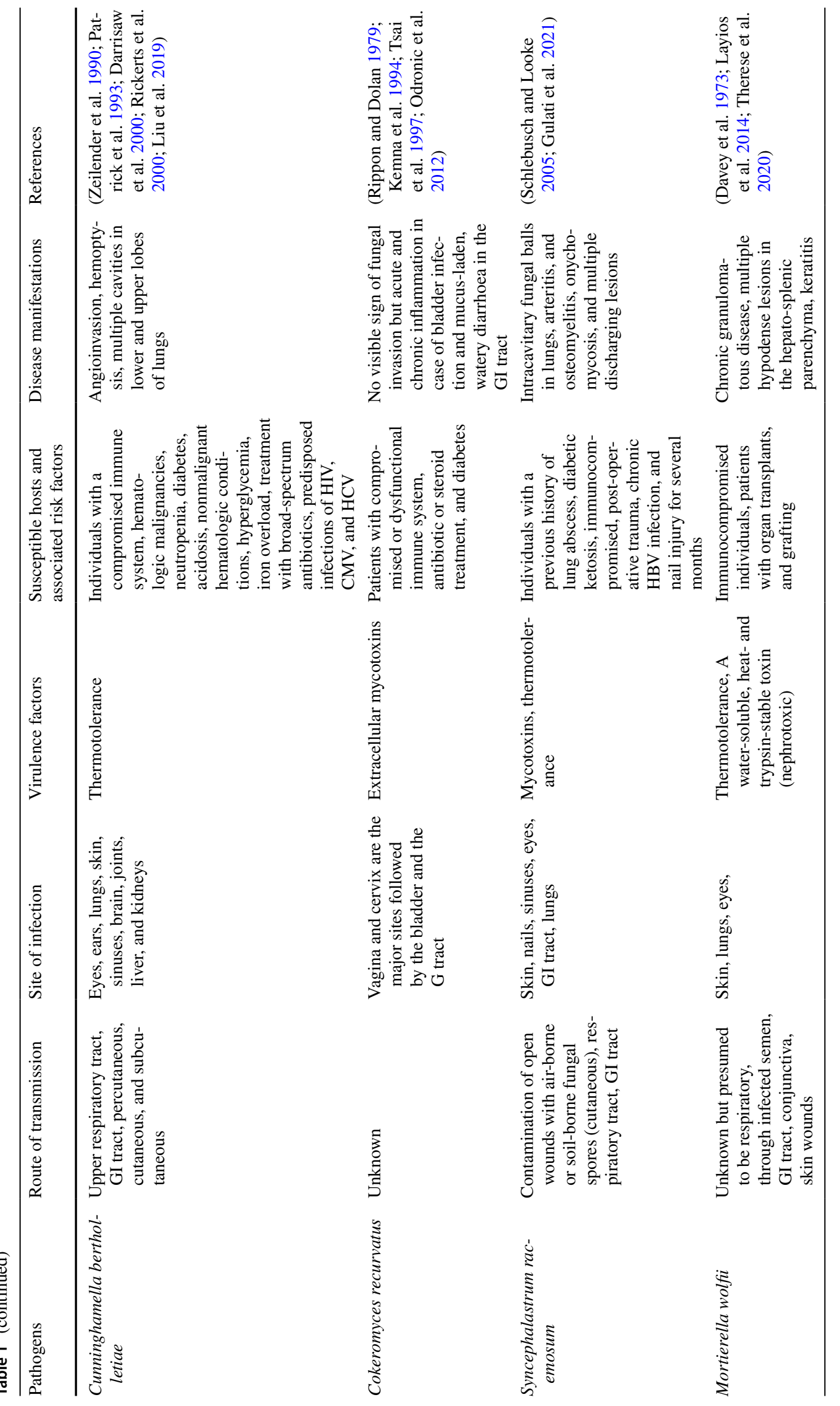


subunit has potent role over the expression of ACE-2 gene, hypoxia induced endothelial cell damage, and upregulation of innate and adaptive immune cells (Herrmann et al. 2020; Rahman et al. 2021). The overall impact of HIF-1 results into increased localized inflammation and tissue damage in COVID-19 patients. Besides, COVID-19 infection has also been shown to change iron metabolism. Several reports have suggested hyperferritinemic syndrome following COVID-19 infection. High levels of free iron result into tissue damage through production of free oxygen radicals (Vargas-Vargas and Cortés-Rojo 2020; Shoenfeld 2020; Perricone et al. 2020; Gómez-Pastora et al. 2020; Sonnweber et al. 2020). Furthermore, during the treatment of COVID-19, use of immunosuppressant's and corticosteroids are warranted to reduce the inflammation in the lungs and restrain the damage caused by cytokine storm. Steroids assist to curb the inflammation but it also suppresses the immune system, and could also trigger the uncontrolled release of sugar. Moreover, to overcome COVID-19 mediated hypoxia, use of oxygen masks and ventilators is essential. These potential factors make COVID-19 infected person more vulnerable to mucormycosis.

\section{C. possible patho-mechanism of CAM}

The main symptoms of COVID-19 such as hypoxia, hyperglycemia, hyperferritinemia, increased body temperature, and altered osmolarity, constitute an ideal environment for growth and development of mucormycosis causing fungi (Fig.1). Besides, if the oxygen masks or cylinders used in ventilators are contaminated with the spores of Mucorales, they serve as an entry pass of the spores into the COVID-19 infected patients. As steroid treatment results in immunosuppression, the spores easily enter the hosts system and germinate. The prevailing conditions in COVID-19 patients such as hyperglycemia and hyperferritinemia aid in rapid growth and multiplication of the fungal hyphae (Mahalaxmi et al. 2021).

Besides, several other important factors such as diabetes mellitus (DM), diabetic ketoacidosis (DKA), immune impairment, neutropenia, metabolic dysfunction, treatment condition with iron elevators, thrombocytopenia, treatment with voriconazole render the individuals more susceptible to the infection of mucormycosis (Ibrahim et al. 2012; Petrikkos and Tsioutis 2018). As this fungal infection is life threatening, and opportunistic, vigorous studies with experimental evidences are warranted to understand its pathogenesis especially in the individuals affected with COVID-19. A future

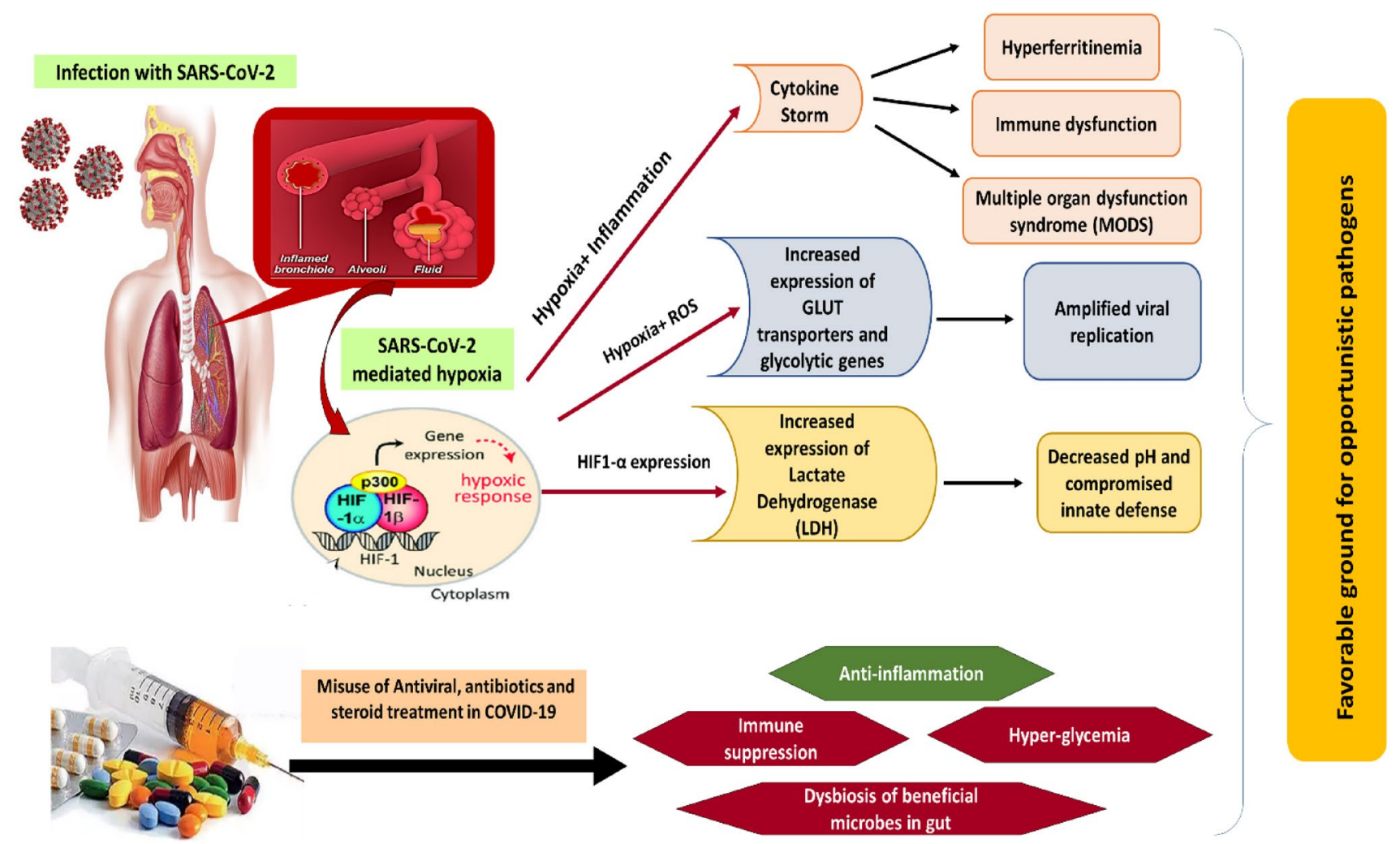

Fig. 1 SARS-CoV-2 infection and the associated outcomes laying the foundation for secondary infections to pitch in. Hypoxia-inducible factor- $1 \alpha(\mathrm{HIF}-1 \alpha)$; reactive oxygen species (ROS), glucose transporters (GLUT) 
research on CAM would be instrumental in early diagnosis and management of this tangled duo.

\section{Rapid detection of mucormycosis}

The joint clinical guideline from the European Society for Clinical Microbiology and Infectious Diseases (ESCMID) and the European Confederation of Medical Mycology (ECMM) emphasizes the diagnosis and management of mucormycosis. The most widely used methods for detecting mucormycosis have been summarized here.

\section{A. Diagnostic imaging}

The most common clinical presentation of mucormycosis is rhino-cerebral, pulmonary, soft tissue, and disseminated disease. Although tissue necrosis is the hallmark of mucormycosis, its detection and early diagnosis lack sensitivity and specificity (Skiada et al. 2018). Computed tomography (CT) findings have been crucial in the early detection of pulmonary or spinal lesions, which includes halo signs, reverse halo signs, cavities with pleural effusion, nodules, and wedge-shaped infiltrates. These are considered signatures of angio-invasive fungi (Walsh et al. 2012). The presence of RHS along with more than ten pulmonary nodules, and pleural effusion are the most distinguishing characteristics of mucormycosis from aspergillosis (Skiada et al. 2018). Although CT scan provides a detailed picture of the organs/ tissue under study, combining it with positron emission tomography (PET) scan is recommended due to its sensitivity and higher accuracy to precisely point out anatomic abnormality (Liu et al. 2020). Magnetic resonance imaging is useful for assessing the extent of fungal disease in soft tissues (Yasmin et al. 2021). In addition to anatomic imaging modalities, functional and metabolic imaging using (PET/CT) coupled with [18F]-fluorodeoxyglucose (FDG) has been considered a valuable tool in the diagnosis and management of mucormycosis. Several reports have demonstrated an increased FDG uptake at the site of lesion upon diagnosis with FDG PET/CT during mucormycosis, and after antifungal therapy, the FDG uptake was reduced at the infection site (Dang et al. 2012; Liu et al. 2013; G Díaz et al. 2019; Song 2019; Gallo et al. 2019). Currently there are no reports supporting use of any particular technique in diagnosis of CAM. However, certain diagnostic imaging techniques based on the case reports have used high resolution computed tomography (HRCT), PET/CT, and 18F- FDGPET/CT to evaluate structure of lungs in case of COVID-19 associated pulmonary mucormycosis (Dilek et al. 2021). (MRI) and 18F- FDG-PET/CT has been used for diagnosis of COVID-19 associated rhino-sinusal or rhino-orbitocerebral mucormycosis. While, for patients with COVID-19 associated rhino-facial mucormycosis, CT scan was used for diagnostic imaging (Garg et al. 2021; Mohammadi et al. 2021). Besides, recognition of patient's risk factors and careful assessment of clinical manifestations by use of imaging techniques would contribute significantly to the early diagnosis of mucormycosis. Further, a definitive diagnosis with a culture-based and molecular approach could be considered for initiating the appropriate antifungal therapy.

\section{B. Microscopy and culture-based examination}

The traditional detection methods in mycology include microscopy, histology, fungal culture, and serology. Direct mycological inspection of wide, non-septate, ribbon-like, hyaline hyphal elements in black chlorazol solution is the key feature related to Zygomycetes, which could be further supported by fungal culture (Machouart et al. 2006). For culture-based examination of mucormycosis-related clinical specimens, the use of fungal culture media, such as Sabouraud agar and potato dextrose agar is considered followed by its incubation $37^{\circ} \mathrm{C}$. All Mucorales grow on these media in 2-7 days but for some species, a microaerophilic environment improves culture yield (Lass-Flörl and Mayr 2009). However, the culture-based approach is not completely reliable because even when fungal hyphae are seen in histopathological analysis, fungal cultures are only positive in $50 \%$ of cases (Walsh et al. 2012). This is usually attributed to the fragile nature of fungal hyphae, which is prone to damage during tissue grinding or homogenization (Kontoyiannis et al. 2007). Histopathological examination of the infected tissue would allow a keen differentiation between the hyphae of Mucorales and closely related fungi such as Aspergillus or Penicillium (Song et al. 2020). The typical hyphae of Mucorales genera are non-pigmented, wide (5-20 $\mu \mathrm{m})$, thinwalled, ribbon-like, pauciseptate hyphae with right-angle branching. As mucormycosis is characterized by angioinvasion, perineural invasion, and prominent infarcts, an accurate examination would be critical for the choice of treatment. A rapid presumptive diagnosis of mucormycosis could be done through direct histopathological examination of the tissue through fluorescence microscopy using fluorescent brighteners such as Blankophor and Calcofluor White, which bind to chitin and cellulose in the fungal cell wall and fluoresce under ultraviolet (UV) light (Cornely et al. 2014).

\section{Serological methods}

Currently, there are no routine serological tests used for the diagnosis of mucormycosis. However, based on the specific antigens, techniques such as immunohistochemistry, Enzyme-linked immunosorbent assays, immunoblots, and immunodiffusion tests could be further evaluated for commercial use (Wysong and Waldorf 1987; Cornely et al.

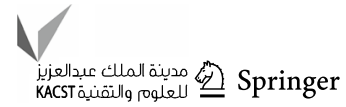


2014). Additionally, a study by Potena et al., demonstrated Mucorales-specific T cells in a group of 28 hematologic patients with invasive mucormycosis using enzyme-linked immunospot (ELISpot) assay. Interestingly, none of the control group patients showed Mucorales-specific T cells, indicating its potential use as a reliable marker for the diagnosis of invasive mucormycosis (Potenza et al. 2011). Serum tests involving the use of 1,3-beta-D-glucan assay yield confounding results for the Mucorales group (Kontoyiannis 2016). This is because, as compared to other fungal pathogens, the dearth in understanding the cell wall structure and components of Mucorales. However, certain polysaccharides such as mucoran, mucoric acid, chitin, chitosan, and mannose have been reported as major components of the cell wall, while the presence of glucan has been demonstrated only in the spore cell wall of Mucor circinelloides, M. ramannianus, and Rhizopus oryzae (Lecointe et al. 2019).

\section{Molecular methods}

Molecular techniques are promising for rapid, sensitive, and accurate identification of pathogenic fungi causing mucormycosis (Voigt et al. 1999; Wu et al. 2003). This includes the use of polymerase chain reaction (PCR), restriction fragment length polymorphism analyses (RFLP), DNA sequencing of internal transcribed spacer ITS or 18S rRNA gene region for detection or identification of Mucorales (Lackner et al. 2014). A study by Machouart et al., demonstrated the use of a rapid and sensitive direct PCR-RFLP technique on a histopathological sample, for the identification of Mucorales in human pathology. This involved selective amplification of genomic DNA from molds followed by digestion step with restriction enzymes for species-level identification and further antifungal susceptibility testing (Machouart et al. 2006). In another study, the $18 \mathrm{~S}$ rDNA and the D1-D2 domains of the $28 \mathrm{~S}$ rDNA were identified for 42 isolates of Zygomycetes and 13 taxon-specific PCR primer pairs were designed for rapid and accurate identification of etiological agents of mucormycosis (Voigt et al. 1999). Scherer et al., demonstrated the use of, real-time, quantitative PCR (qPCR) assays, with $28 \mathrm{~S}$ rDNA of Mucorales from bronchoalveolar lavage fluid, for rapid and accurate detection of invasive pulmonary mucormycosis (Scherer et al. 2018). Thus, given the increase in the number of cases with mucormycosis, the use of these molecular tools can be escalated for rapid and accurate identification of Mucorales from a pure culture.

\section{E. Advances in fungal detection and emerging methods}

Recent advancement in fungal diagnostics is the application of Matrix-assisted laser desorption ionization-time of flight mass spectrometry of (MALDI-TOF MS) that identifies species-specific fungal peptides The Food and Drug Administration (FDA) approved commercially available MALDITOF MS platforms, are Bruker Biotyper (Germany) and Vitek MS (France). The advantage of this technique lies in the rapid identification of fungal isolates or direct clinical specimens in 30 min (Yan et al. 2011; Spanu et al. 2012; Lau et al. 2019). Another FDA-approved commercial platform is 2 Magnetic Resonance (T2MR) (T2 Biosystems). This technique has been used for detecting pathogenic $\mathrm{Can}$ dida spp. Here, the clustering/complex between particles coated with target-specific agents is observed with the target pathogen with the altered microenvironment of the surrounding water molecules, which is detected and quantified by T2MR. Although individual sample costs are high, this technique can detect low levels of Candida cells within $5 \mathrm{~h}$ (Mylonakis et al. 2015; Zacharioudakis et al. 2018). Therefore, considering the current scenario, this technique could be a valuable tool for early (as it can detect low levels of fungal cells) and rapid detection of mucormycosis causing pathogens by escalating development of particles coated with Mucorales-specific agents. Additionally, a study by Koshy et al., suggested the use of breath-based biosensors for the diagnosis of IM. In this study, the volatile sesquiterpene metabolite profiles from the breath of murine models were analyzed using thermal desorption gas chromatography/tandem mass spectrometry (GC-MS/MS), and it was found that each Mucorales species produced a consistent profile of sesquiterpene secondary metabolite, which can be distinguished from aspergillosis (Koshy et al. 2017).

Biosensor technologies have been used for the direct detection of fungal pathogens. Biosensors are analytical devices that detect the concentration of bio-analyte and convert the physical or chemical signal into electrochemical or optical signals. Based on the technology, there are four types of biosensors: optical, electrochemical, thermal, and piezoelectric (Samson et al. 2020). Cai et al., has demonstrated optical detection of cell surface mannan of Candida albicans binding to hydrogel Con-A using a photonic crystal sensor (Cai et al. 2015). In a study by Bhatnagar et al., a sensitive electrochemical nanobiosensor fabricated with 1,6-Hexanedithiol and chitosan-stabilized gold nanoparticles was designed for rapid detection of Aspergillus fumigatus (Bhatnagar et al. 2018). Another study by Asghar et al., developed an immuno-based microfluidic chip that can rapidly detect and capture $C$. albicans from phosphate-buffered saline (PBS) and human whole blood (Asghar et al. 2019). Since biosensors have not been much explored for detecting fungal pathogens, it could be an active area for current interdisciplinary research. Likewise, given the current epidemic situation, the development of biosensors would be of immense importance for the rapid and early detection of mucormycosis, and would also aid in monitoring treatment response based on specific marker analytes (Fig. 2). A wide range of fungal biomarkers such as mannan, galactomannan, 


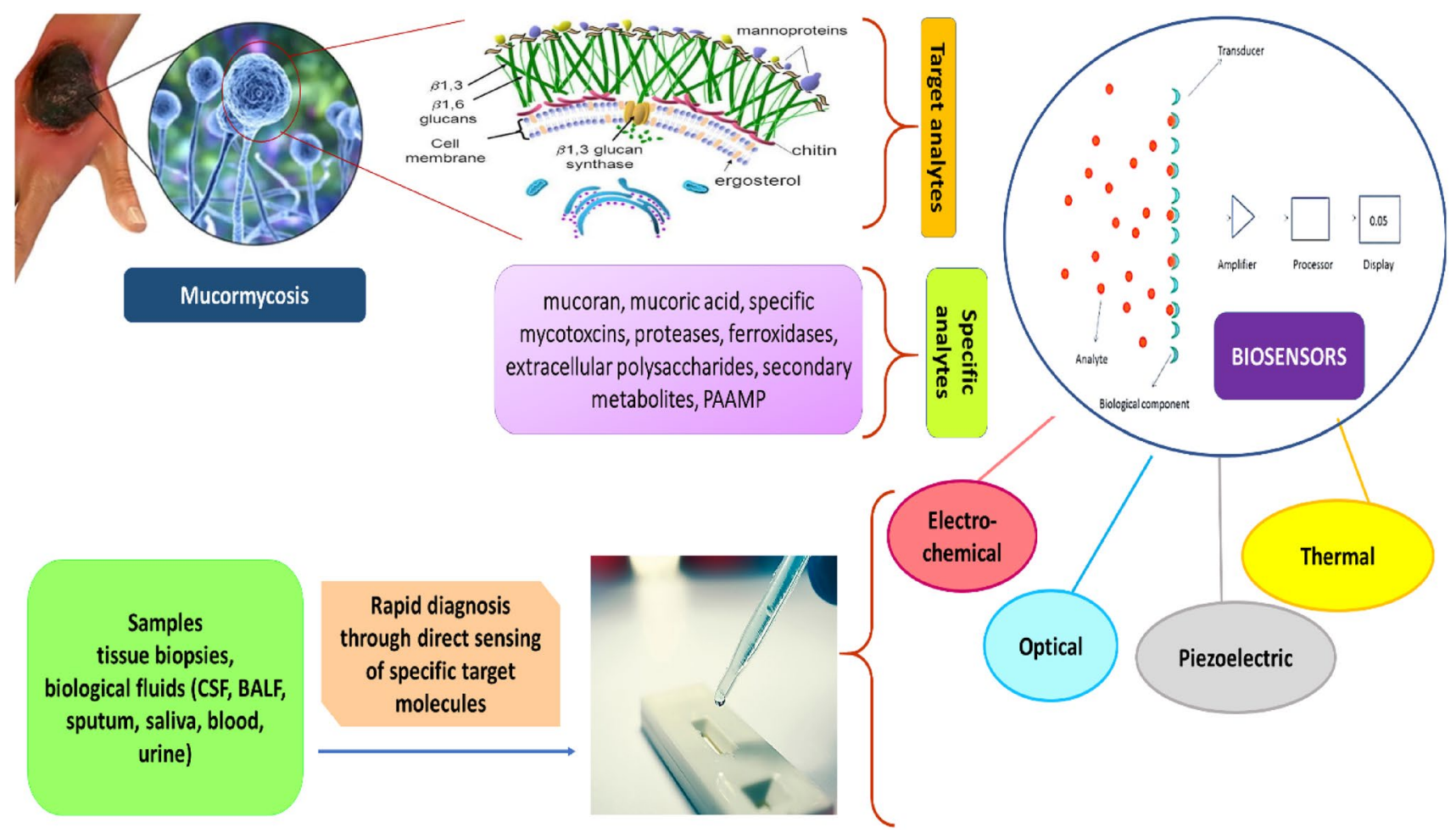

Fig. 2 Schematic illustration of target and specific analytes for development of biosensors for mucormycosis causing fungal pathogens

mannan, beta-glucan and cryptococcal antigen, have been explored for the development of diagnostic tests. In case of mucormycosis, there are no specific biomarkers for rapid identification. However, to the best of our knowledge only one study by Orne et al., where lateral flow immunoassay (LIFA) technique was developed by using monoclonal antibody (mAb 2DA6) against cell wall fucomannan of Mucorales. The monoclonal antibody mAb 2DA6 is extremely sensitive for fucomannan due to its apparent low-level of side chain substitution. This was then used as a biomarker for rapid diagnosis of invasive murine mucormycosis (Orne et al. 2018). However, no further studies were carried out with this biomarker to develop advanced techniques for rapid detection of mucormycosis. Therefore, considering its sensitivity, mAb 2DA6 based biosensors could be developed and employed for early diagnosis and rapid detection of CAM. Based on all the above-described detection methods, the use of a multidisciplinary approach for rapid detection and appropriate treatment of mucormycosis in patients could be instrumental in reducing the mortality rate of these infections.

\section{Management of mucormycosis}

Effective management of mucormycosis is a multimodal approach involving early, rapid detection and prompt treatment for effective prognosis. An optimal management relies upon recognizing the various patterns of the disease along with convenient diagnostic and therapeutic choices.

\section{A. Reversal of the underlying condition}

It is of pivotal importance to reverse or prevent the underlying disease/medical condition/immune dysfunction in the patients while treating them for mucormycosis. The use of immunosuppressant, in particular corticosteroids should be minimized or terminated if possible (Spellberg and Maertens 1991). Moreover, to reduce the severity of mucormycosis infections, administration of iron and blood transfusions should be avoided. Similarly, use of DFO should be minimized as it is known to aggravate mucormycosis. Besides, for patients with ketoacidosis and DM, a rapid restoration of euglycemia, and normal acid base status is crucial (Spellberg et al. 2009).

\section{B. Surgical management}

As per the global guidelines by The European Confederation of Medical Mycology (ECMM) jointly with the International Society for Human and Animal Mycology (ISHAM), and ECMM together with the Mycoses Study Group Education \& Research Consortium (MSG ERC), an early and meticulous surgical resection and debridement of the tissue affected with mucormycosis is of pivotal

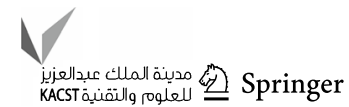


importance in localizing the spread of mucormycosis (Cornely et al. 2019). As the surgical treatment vastly depends on the site and extent of the disease, it is a preferred choice of treatment for rhino-orbito-cerebral and soft tissue mucormycosis. Additionally, for patients with pulmonary or disseminated mucormycosis, surgery could be considered on case-by-case basis (Skiada et al. 2013). A recent report by Claustre et al., suggested curative surgery to be the key survival factor for mucormycosis in patients with hematological malignancies (Claustre et al. 2020). In another study involving evidence-based mapping of CAM patients, a higher percentage of survival (64.96\%) was observed for those who underwent antifungal therapy in adjunct to surgical debridement (Hussain et al. 2021). Thus, prompt surgical intervention is crucial in ameliorating the fatal outcomes of CAM. However, the subsequent prognosis would essentially depend on the infection site, spectrum, and etiology of the fungus, and the associated comorbidities. In cases of disseminated mucormycosis or absence of removal of infected focus, surgical management becomes challenging, and the antifungal therapy singly is seldom curative (Chibucos et al. 2016). Hence, surgical limitations drive the necessity to seek additional alternative strategies for prevention and management of invasive mucormycosis.

\section{Antifungal therapy}

Treatment of mucormycosis encompasses the use of antifungal agents along with surgical debridement. As per the recommendations by ECMM and MSG- ERC, the primary prophylaxis involves treatment of mucormycosis patients having comorbidities such as neutropenia or bone marrow transplant with moderate strength posaconazole tablets or its marginal strength oral suspension. The secondary prophylaxis includes treatment of mucormycosis affected immunosuppressed patients with surgical resection together with continuation of the last drug effective in that patient (Cornely et al. 2014).

\section{C1: Primary antifungal therapy}

Primary therapy includes use of polyenes. The only licensed antifungal for mucormycosis is Amphotericin B deoxycholate. However, to overcome its substantial nephrotoxicity and poor CNS penetration, lipid formulation of amphotericin B $(5 \mathrm{mg} / \mathrm{kg}-10 \mathrm{mg} / \mathrm{kg})$, is administered as a safer and efficacious alternative for the treatment of mucormycosis (Walsh et al. 2008; Lewis et al. 2010). Besides, moderate strength isavuconazole, and posaconazole are also recommended as first-line antifungal monotherapy (Kyvernitakis et al. 2016).

\section{C2: Primary combination therapy}

There are no convincing studies to support the use of combination of antifungals in therapeutic regime of mucormycosis, and therefore, it is not included as major treatment guidelines. However, use of combination of antifungals in step-down therapy is warranted (Honavar 2021). In this combination therapy, use of broad-spectrum azoles such as posaconazole and isavuconazole in the form of oral or parenteral formulation could be used as a step-down therapy or as a salvage therapy for patients who are intolerable or do not respond to amphotericin B (Kauffman 2019). Also, itraconazole and terbinafine could be used depending on different strains of Mucorales (Skiada et al. 2018). A recent retrospective review by Reed et.al, suggested combination of polyene-caspofungin therapy as a promising alternative for ROCM patients treated with polyene monotherapy (Reed et al. 2008). Since the duration of treatment for mucormycosis remain unknown, it should be continued until the indicative findings through imaging have been resolved along with improvement of the hosts' immune system. Additionally, administration of isavuconazole or posaconazole could be considered as maintenance therapy (Kontoyiannis and Lewis 2011).

\section{D: Adjunct therapy}

\section{D1: Iron chelators}

Iron is fundamental for growth and virulence of microbial pathogens. Patients with elevated an increased serum iron levels are susceptible to mucormycosis. Iron metabolism plays an important role in infections with Mucorales, and therefore, use of iron chelators as an adjunctive therapy is important (Roilides et al. 2003; Bullen et al. 2006). Iron chelators have higher affinity constants for iron and therefore, prevent the accumulation of excess iron and challenge the fungal growth with the iron-depleting environment (Symeonidis 2009). Food and drug administration (FDA) approved iron chelators include oral tablets such as Deferiprone (DFP), Deferasirox (DFX), and injectable Desferrioxamine (DFO) (Scott et al. 2021). DFO received FDA approval for treating iron overload in transfusion-dependent anemia in the year 2005. This led to its unapproved use as an adjunctive therapy in advanced cases of mucormycosis, particularly in patients with underlying diabetic ketoacidosis (DKA). Further, as compared to DFO, DFP and DFX, do not increase susceptibility to mucormycosis. DFP and DFX have been reported to have antifungal activity in-vitro and invivo against Mucorales, and therefore, are used as effective iron chelators in clinical practice (Mahalmani et al. 2021). In CAM, iron is fundamental for the growth and life cycle of the mold. Hence, the use of iron chelators to regulate 
the iron concentration in the body would be imperative. Till date there are limited scientific evidences with respect to use of iron chelators in CAM. Therefore, a combinatorial approach of non-xenosiderophore iron chelators and antifungal agents could be employed in the treatment regime for their possible synergistic effect. Additionally, comprehensive studies evaluating the role of combined antifungals and iron chelators would be insightful in efficient management of mucormycosis.

\section{D2: Cytokines}

Cytokines are an integral part of the viable innate antifungal host defenses. Particularly, interferon- $\gamma($ IFN- $\gamma$ ) and granulocyte-macrophage colony-stimulating factor (GMCSF) are the critical in immunomodulation of invasive fungal infections (Roilides et al. 2003). A study by GilLamaignere et al., showed enhanced antifungal activity of human polymorphonuclear leukocytes (PMNLs) against $R$. oryzae and $R$. microsporous, by using pro-inflammatory cytokines IFN- $\gamma$ and GM-CSF, thereby suggesting, use of these cytokines in management of invasive mucormycosis (Gil-Lamaignere et al. 2005). Besides, several case reports have also suggested use of recombinant GM-CSF and granulocyte colony-stimulating (G-CSF) as an adjuvant therapy in management of invasive mucormycosis (Mastroianni 2004; Abzug and Walsh 2004; Spellberg et al. 2009). Additionally, G-CSF in combination with antifungal therapy has been employed as secondary prophylaxis in treatment of mucormycosis in patients with hematological malignancies (Grigull et al. 2006). Another recent study by dos Santos et al., suggested critical role of IFN- $\gamma$ in enhancing fungal clearance of pulmonary mucormycosis in mice (dos Santos et al. 2021). This is because, IFN- $\gamma$ induces a T-helper cell type 1 (Th1) cells and the subsequent immunological response enhances the antifungal activities of PMLs' and favors resistance to invasive fungal infections Although, the reported evidences with cytokines therapy for mucormycosis are limited, it would be an important area of future research to determine their role in primary treatment. Also, rigorous clinical trials are essential to warrant the use of GM-CSF, G-CSF, and IFN- $\gamma$ auxiliary to the conventional antifungal treatment.

\section{D3: Hyperbaric oxygen}

The use of hyperbaric oxygen therapy (HBOT) as an adjunctive treatment for mucormycosis was first described in 1970. In this, $100 \%$ of oxygen is administered to the patients through masks or endotracheal tubes. The pressure inside the chambers is increased to $250-280 \mathrm{kPa}$, and the partial pressure of oxygen $\left(\mathrm{PaO}_{2}\right)$ is $\sim 1200-2000 \mathrm{mmHg}$. In-vitro studies have shown antifungal activity of HBOT at pressures
$<10$ atm (Gudewicz et al. 1987; Galiazzo et al. 1987). There are several reports highlighting the direct antifungal effect of hyperbaric oxygen under hyper-oxic conditions due to increased production of oxygen based free radicals (Couch et al. 1988; Ferguson et al. 1988; Arnáiz-García et al. 2009; Ezra et al. 2011; Valente Aguiar et al. 2021). Additionally, HBOT have several indirect antimicrobial effects which includes restoration of phagocytosis, reversal of lactic acidosis, enhanced oxidative burst of PMLs and augmented antifungal action of amphotericin B (Siddiqui et al. 1997; John et al. 2005; Mathieu and Wattel 2006; Bitterman 2007; Tragiannidis and Groll 2009). Data supporting the clinical efficacy of HBOT in invasive mucormycosis is still limited. However, a comprehensive review by John et al., described use of HBOT as an adjunct therapy to treat zygomycosis. Of the total 28 patients, $81 \%$ had underlying conditions such as DM (61\%), trauma (18\%), HM (11\%), alcoholic liver disease (7\%), treatment with corticosteroids (3\%). The remaining $11 \%$ had no underlying conditions. The overall survival rate after treatment was 86\% (John et al. 2005). Although HBOT has been used to treat zygomycosis, the clinical evidence for its use in mucormycosis remain anecdotal and inconclusive. Therefore, further experimental studies are essential to evaluate the clinical efficacy of HBOT in CAM. This would be critical to determine the outcome and impact of this treatment in management of CAM.

\section{Probiotics: an experimental potential future management alternative}

Probiotics are live microorganisms that, when expended in appropriate amounts, confer a health benefit to the host (Gohil et al. 2021). Besides having anti-inflammatory activity, probiotics are also known to have anti-fungal and antimycotoxigenic activities (Dalié et al. 2010; Aiko et al. 2016; Russo et al. 2017; Arasu and Al-Dhabi 2017; Azizkhani et al. 2021). A study by Lipinska et al., had shown enhanced antifungal activity of 60 Lactobacillus sp. strains against selected food contaminating fungi such as Alternaria alternata, A. brassicicola, Aspergillus niger, Fusarium latenicum, Geotrichum candidum, Candida vini, and Mucor hiemalis, in presence of xylitol and galactosyl-xylitol (Lipińska et al. 2016). Another study by Karami et al., indicated a significant antifungal effect of two species of Lactobacillus viz $L$. alimentarius and $L$. delbrueckii on Penicillium notatum and Aspergillus fulvous (Karami et al. 2017). Lactobacillus spp. has also been demonstrated to have antifungal activity against Candida spp. isolated from the patients with AIDS with HIV (Salari and Ghasemi Nejad Almani 2020), and against planktonic cells, biofilms, and persister cells of C. auris through postbiotic elements (Rossoni et al. 2018). 
Details of probiotics and their immunomodulatory effects in fungal infections have been comprehended in Table. 2.

Recent meta-analysis by $\mathrm{Hu}$ et al., showed efficacy of probiotic bacteria in prevention and treatment of oral candidiasis in both animal experiments and in clinical trials. The possible mechanism behind prophylactic activity could be competition of probiotic species with the pathogens for nutrients and binding receptors, and release of certain metabolites which inhibits or antagonizes the growth of Candida spp (Hu et al. 2019). Several other studies have also shown in-vivo efficacy and safety of probiotics in treatment of candidiasis and other fungal infections (Brzozowski et al. 2005; Vicariotto et al. 2012; Demirel et al. 2013; Matsubara et al. 2016; Silva et al. 2016). Although the role of probiotics as antifungal agents has been well known, to date there are no experimental evidences supporting or evaluating the role of probiotics in treatment or prophylaxis of CAM. However, there are several reports and experimental studies highlighting the importance of use of probiotics as an adjunctive or prophylactic treatment for COVID-19 (He et al. 2020; Morais et al. 2020; Olaimat et al. 2020; Gohil et al. 2021; Chhibber-Goel et al. 2021). To date, four clinical studies have used probiotics in management of COVID-19 and around six studies are being assessed for the clinical trials (Baindara et al. 2021; Tang et al. 2021; Peng et al. 2021) Therefore, on the basis of the existing fundamental studies, future research could be directed toward assessing the efficacy of probiotics singly or as an adjunct with the existing management strategies in treatment of CAM. Thus, probiotics could be used to tackle the triple threat of COVID-19 i.e., as a replenisher of gut dysbiosis, as an anti-inflammatory agent, and as an antimicrobial (antifungal) agent.

\section{Conclusion and prospects}

Crisis brings opportunity, and the time to act on mucormycosis is now. The rapid increase in mucormycosis infection and the associated fatality is alarming. The clinical symptoms are elusive and the use of conventional techniques for detection/diagnosis is time-consuming, insensitive, and unspecific (Skiada et al. 2018). Therefore, there is an urgent need for developing methods for rapid detection of mucormycosis and appropriate antifungal management. Currently, combining the culture-based method with molecular methods or advanced techniques such as MALDI-TOF, GC MS/MS, T2MR would significantly improve the diagnosis of mucormycosis. Further, the emerging biosensor platforms could be developed by combining specific molecular biomarkers or species-specific recognition elements to address the rapid detection challenge of mucormycosis. Also, advancement in microchipbased or implantable biosensors for continuous monitoring of fungal analytes during treatment would be crucial to highlight the critical points during therapeutic intervention. For effective management of CAM, antifungal agents with iron chelators could be used. Moreover, the use of probiotics could be beneficial in tackling mucormycosis/ CAM and achieving immune homeostasis.

Table 2 Antifungal activity of probiotics in fungal infections

\begin{tabular}{|c|c|c|c|c|c|}
\hline Sr. No & Probiotic microbes & $\begin{array}{l}\text { Immunomodulatory activ- } \\
\text { ity of the probiotic }\end{array}$ & Activity against & $\begin{array}{l}\text { Useful in combat- } \\
\text { ing disease/condi- } \\
\text { tion }\end{array}$ & References \\
\hline 1 & $\begin{array}{l}\text { L. fermentum } 20.4, L . \\
\text { paracasei } 28.4, L \\
\text { rhamnosus, Pediococcus } \\
\text { acidilactici. HW01 }\end{array}$ & $\begin{array}{l}\text { Biosurfactant produced } \\
\text { by the organism reduces } \\
\text { adhesion and biofilm } \\
\text { formation of the fungus }\end{array}$ & Candida albicans & Candidiasis & $\begin{array}{l}\text { (Rossoni et al. 2018; Kim } \\
\text { and Kang 2019) }\end{array}$ \\
\hline 2 & $\begin{array}{l}\text { Saccharomyces cerevisiae } \\
\text { KTP }\end{array}$ & $\begin{array}{l}\text { Adhesion, filamentation } \\
\text { and biofilm formation }\end{array}$ & Candida krusei & Candidiasis & (Kurrey et al. 2019) \\
\hline 3 & $\begin{array}{l}\text { L. casei, } L \text {. acidophilus, } L \text {. } \\
\text { paracasei }\end{array}$ & $\begin{array}{l}\text { Decreased pH due to acid } \\
\text { production along with } \\
\text { anti-microbial agents }\end{array}$ & $\begin{array}{l}\text { Aspergillus niger, } A . \\
\text { flavus, } \\
\text { A. parasiticus, } P \text {. chrys- } \\
\text { ogenum }\end{array}$ & Aspergillosis & (Abbaszadeh et al. 2015) \\
\hline 4 & L. plantarum KCC-28 & $\begin{array}{l}\text { Production of hydrolytic } \\
\text { enzymes }\end{array}$ & Fusarium oxysporum & Keratitis & $\begin{array}{l}\text { (Ilavenil et al. 2015; Batista } \\
\text { et al. 2020) }\end{array}$ \\
\hline 5 & $\begin{array}{l}\text { Lactobacillus harbinen- } \\
\text { sis } \mathrm{K} . \mathrm{V} 9.3 .1 \mathrm{~Np}\end{array}$ & No observation & $\begin{array}{l}\text { Yarrowia lipolytica, } \\
\text { Kluyveromyces marxi- } \\
\text { anus, Penicillium brevi- } \\
\text { compactum }\end{array}$ & Food poisoning & (Delavenne et al. 2013) \\
\hline 6 & $\begin{array}{l}\text { Leuconostoc mesenter- } \\
\text { oides }\end{array}$ & $\begin{array}{l}\text { Bioactive compound } \\
\text { production }\end{array}$ & $\begin{array}{l}\text { Meyerozyma guilliermon- } \\
\text { dii, P. roqueforti, Asper- } \\
\text { gillus oryzae }\end{array}$ & Food poisoning & (Yépez et al. 2017) \\
\hline
\end{tabular}




\section{Declarations}

Conflict of interest The authors declare no conflict of interest.

\section{References}

Abbaszadeh S, Tavakoli R, Sharifzadeh A, Shokri H (2015) Lactic acid bacteria as functional probiotic isolates for inhibiting the growth of Aspergillus flavus, A. parasiticus, A. niger and Penicillium chrysogenum. J Mycol Med 25:263-267. https://doi.org/10. 1016/j.mycmed.2015.10.011

Abzug MJ, Walsh TJ (2004) Interferon-gamma and colony-stimulating factors as adjuvant therapy for refractory fungal infections in children. Pediatr Infect Dis J 23:769-773. https://doi.org/10. 1097/01.INF.0000134314.65398.BF

Aiko V, Edamana P, Mehta A (2016) Decomposition and detoxification of aflatoxin B1 by lactic acid. J Sci Food Agric 96:1959-1966. https://doi.org/10.1002/jsfa.7304

Arasu MV, Al-Dhabi NA (2017) In vitro antifungal, probiotic, and antioxidant functional properties of a novel Lactobacillus paraplantarum isolated from fermented dates in Saudi Arabia. J Sci Food Agric 97:5287-5295. https://doi.org/10.1002/jsfa.8413

Arnáiz-García ME, Alonso-Peña D, del Carmen G-V et al (2009) Cutaneous mucormycosis: report of five cases and review of the literature. J Plast Reconstr Aesthetic Surg. https://doi.org/10. 1016/j.bjps.2008.04.040

Artis WM, Fountain JA, Delcher HK, Jones HE (1982) A mechanism of susceptibility to mucormycosis in diabetic ketoacidosis transferrin and iron availability. Diabetes 31:1109-1114. https://doi. org/10.2337/DIACARE.31.12.1109

Asghar W, Sher M, Khan NS et al (2019) Microfluidic chip for detection of fungal infections. ACS Omega 4:7474-7481. https://doi. org/10.1021/acsomega.9b00499

Azizkhani M, Saris PEJ, Baniasadi M (2021) An in-vitro assessment of antifungal and antibacterial activity of cow, camel, ewe, and goat milk kefir and probiotic yogurt. J Food Meas Charact 15:406415. https://doi.org/10.1007/s11694-020-00645-4

Baindara P, Chakraborty R, Holliday ZM et al (2021) Oral probiotics in coronavirus disease 2019: connecting the gut-lung axis to viral pathogenesis, inflammation, secondary infection and clinical trials. New Microbes New Infect 40:100837. https://doi.org/ 10.1016/J.NMNI.2021.100837

Baldin C, Ibrahim AS (2017) Molecular mechanisms of mucormycosis-the bitter and the sweet. PLoS Pathog. https://doi.org/10. 1371/journal.ppat.1006408

Batista BG, de Chaves MA, Reginatto P et al (2020) Human fusariosis: an emerging infection that is difficult to treat. Rev Soc Bras Med Trop 53:1-7

Bhatnagar I, Mahato K, Ealla KKR et al (2018) Chitosan stabilized gold nanoparticle mediated self-assembled gliP nanobiosensor for diagnosis of invasive Aspergillosis. Int J Biol Macromol 110:449-456. https://doi.org/10.1016/j.ijbiomac.2017.12.084

Binder U, Maurer E, Lass-Flörl C (2014) Mucormycosis-from the pathogens to the disease. Clin Microbiol Infect 20:60-66

Bitterman H (2007) Oxygen: an anti-inflammatory drug. Isr Med Assoc J 9:874-876

Blomberg B, Manji KP, Urassa WK et al (2007) Antimicrobial resistance predicts death in Tanzanian children with bloodstream infections: a prospective cohort study. BMC Infect Dis 7:1-5. https://doi.org/10.1186/1471-2334-7-46

Brunke S, Mogavero S, Kasper L, Hube B (2016) Virulence factors in fungal pathogens of man. Curr Opin Microbiol 32:89-95. https:// doi.org/10.1016/J.MIB.2016.05.010
Brzozowski T, Zwolinska-Wcislo M, Konturek PC et al (2005) Influence of gastric colonization with Candida albicans on ulcer healing in rats: effect of ranitidine, aspirin and probiotic therapy. Scand J Gastroenterol 40:286-296. https://doi.org/10.1080/ 00365520510011524

Bullen JJ, Rogers HJ, Spalding PB, Ward CG (2006) Natural resistance, iron and infection: a challenge for clinical medicine. J Med Microbiol 55:251-258. https://doi.org/10.1099/JMM.0.46386-0/ CITE/REFWORKS

Cai Z, Kwak DH, Punihaole D et al (2015) A photonic crystal protein hydrogel sensor for Candida albicans. Angew Chemie Int Ed 54:13036-13040. https://doi.org/10.1002/anie.201506205

Chhibber-Goel J, Gopinathan S, Sharma A (2021) Interplay between severities of COVID-19 and the gut microbiome: implications of bacterial co-infections? Gut Pathog 13:1-6

Chibucos MC, Soliman S, Gebremariam T et al (2016) An integrated genomic and transcriptomic survey of mucormycosis-causing fungi. Nat Commun 71(7):1-11. https://doi.org/10.1038/ncomm s12218

Claustre J, Larcher R, Jouve T et al (2020) Mucormycosis in intensive care unit: surgery is a major prognostic factor in patients with hematological malignancy. Ann Intensive Care 10:1-12. https:// doi.org/10.1186/s13613-020-00673-9

Cooter RD, Lim IS, Ellis DH, Leitch IOW (1990) Burn wound zygomycosis caused by Apophysomyces elegans. J Clin Microbiol 28:2151-2153. https://doi.org/10.1128/jcm.28.9.2151-2153.1990

Cornely OA, Arikan-Akdagli S, Dannaoui E et al (2014) ESCMID and ECMM joint clinical guidelines for the diagnosis and management of mucormycosis 2013. Clin Microbiol Infect 20:5-26. https://doi.org/10.1111/1469-0691.12371

Cornely OA, Alastruey-Izquierdo A, Arenz D et al (2019) Global guideline for the diagnosis and management of mucormycosis: an initiative of the European Confederation of Medical Mycology in cooperation with the Mycoses Study Group Education and Research Consortium. Lancet Infect Dis 19:e405-e421

Couch L, Theilen F, Mader JT (1988) Rhinocerebral mucormycosis with cerebral extension successfully treated with adjunctive hyperbaric oxygen therapy. Arch Otolaryngol Neck Surg 114:791-794. https://doi.org/10.1001/archotol.1988.0186019009 5032

Dalié DKD, Deschamps AM, Richard-Forget F (2010) Lactic acid bacteria-potential for control of mould growth and mycotoxins: a review. Food Control 21:370-380

Dang CJ, Li YJ, Zhan FH, Shang XM (2012) The appearance of pulmonary mucormycosis on FDG PET/CT. Clin Nucl Med 37:801803. https://doi.org/10.1097/RLU.0b013e31825ae470

Darrisaw L, Hanson G, Vesole DH, Kehl SC (2000) Cunninghamella infection post bone marrow transplant: case report and review of the literature. Bone Marrow Transplant 25:1213-1216. https:// doi.org/10.1038/sj.bmt.1702395

Davey G, Smith JMB, Kalmakoff J (1973) Purification and properties of a toxin isolated from Mortierella wolfii. Infect Immun 8:882-886. https://doi.org/10.1128/iai.8.6.882-886.1973

Delavenne E, Ismail R, Pawtowski A et al (2013) Assessment of lactobacilli strains as yogurt bioprotective cultures. Food Control 30:206-213. https://doi.org/10.1016/j.foodcont.2012.06.043

Demirel G, Celik IH, Erdeve O et al (2013) Prophylactic Saccharomyces boulardii versus nystatin for the prevention of fungal colonization and invasive fungal infection in premature infants. Eur J Pediatr 172:1321-1326. https://doi.org/10.1007/ S00431-013-2041-4

Díaz LG, López-Corral L, Chinchilla LM et al (2019) Mucormycosis with pulmonary, renal, pancreatic and spleen involvement detected by $18 \mathrm{~F}-\mathrm{FDG}$ PET/CT in a patient who underwent allogeneic stem cell transplantation. Report of case. Trends Transplant. https://doi.org/10.15761/tit.1000260

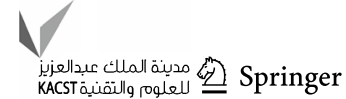


Dilek A, Ozaras R, Ozkaya S et al (2021) COVID-19-associated mucormycosis: case report and systematic review. Travel Med Infect Dis 44:102148. https://doi.org/10.1016/J.TMAID.2021. 102148

dos Santos AR, Fraga-Silva TF, de Fátima A-D et al (2021) IFN- $\gamma$ mediated signaling improves fungal clearance in experimental pulmonary mucormycosis. Mycopathologia. https://doi.org/10. 1007/S11046-021-00598-2

Egge S, Wei E, Clements E, Chandranesan ASJ (2018) Post-traumatic fatal disseminated Apophysomyces elegans infection. Med Mycol Case Rep 22:45-47. https://doi.org/10.1016/j. mmcr.2018.08.002

Ezra N, Dang K, Heuser G (2011) Improvement of attention span and reaction time with hyperbaric oxygen treatment in patients with toxic injury due to mold exposure. Eur J Clin Microbiol Infect Dis 30:1-6. https://doi.org/10.1007/s10096-010-0937-8

Ferguson BJ, Mitchell TG, Moon R et al (1988) Adjunctive hyperbaric oxygen for treatment of rhinocerebral mucormycosis. Rev Infect Dis 10:551-559. https://doi.org/10.1093/CLINI DS/10.3.551

Galiazzo F, Schiesser A, Rotilio G (1987) Glutathione peroxidase in yeast. Presence of the enzyme and induction by oxidative conditions. Biochem Biophys Res Commun 147:1200-1205. https:// doi.org/10.1016/S0006-291X(87)80197-3

Gallo F, Vija L, Le Grand S et al (2019) Diagnosis of an intestinal mucormycosis 'fungus ball' located with PET/CT with [18F] FDG-PET/CT. Eur J Hybrid Imaging 3:1-4. https://doi.org/10. 1186/s41824-019-0068-0

Garg M, Prabhakar N, Muthu V et al (2021) CT Findings of COVID19-associated pulmonary mucormycosis: a case series and literature review. Radiology. https://doi.org/10.1148/radiol.20212 11583

Gebremariam T, Liu M, Luo G et al (2014) CotH3 mediates fungal invasion of host cells during mucormycosis. J Clin Invest 124:237-250. https://doi.org/10.1172/JCI71349

Gebremariam T, Alkhazraji S, Soliman SSM et al (2019) Anti-CotH3 antibodies protect mice from mucormycosis by prevention of invasion and augmenting opsonophagocytosis. Sci Adv 5:13271339. https://doi.org/10.1126/sciadv.aaw1327

Gil-Lamaignere C, Simitsopoulou M, Roilides E et al (2005) Interferon- gamma and granulocyte-macrophage colony-stimulating factor augment the activity of polymorphonuclear leukocytes against medically important zygomycetes. J Infect Dis 191:1180 1187. https://doi.org/10.1086/428503

Gohil K, Samson R, Dastager S, Dharne M (2021) Probiotics in the prophylaxis of COVID-19: something is better than nothing. 3 Biotech. https://doi.org/10.1007/s13205-020-02554-1

Gomes MZR, Lewis RE, Kontoyiannis DP (2011) Mucormycosis caused by unusual mucormycetes, non-Rhizopus, -Mucor, and -Lichtheimia species. Clin Microbiol Rev 24:411-445

Gómez-Pastora J, Weigand M, Kim J et al (2020) Hyperferritinemia in critically ill COVID-19 patients-is ferritin the product of inflammation or a pathogenic mediator? Clin Chim Acta 509:249. https://doi.org/10.1016/J.CCA.2020.06.033

Grigull L, Beilken A, Schmid H et al (2006) Secondary prophylaxis of invasive fungal infections with combination antifungal therapy and G-CSF-mobilized granulocyte transfusions in three children with hematological malignancies. Support Care Cancer 147(14):783-786. https://doi.org/10.1007/S00520-005-0910-8

Gudewicz TM, Mader JT, Davis CP (1987) Combined effects of hyperbaric oxygen and antifungal agents on the growth of Candida albicans. Aviat Sp Environ Med 58:673-678

Gulati N, Gupta P, Nayyar C et al (2021) Syncephalastrum racemosum as a rare agent of rhino-orbital mucormycosis: a case report and review. J Clin Diagnostic Res 15:4-06. https://doi.org/10.7860/ jcdr/2021/47293.14689
Hassan MIA, Voigt K (2019) Pathogenicity patterns of mucormycosis: epidemiology, interaction with immune cells and virulence factors. Med Mycol 57:S245-S256

He LH, Ren LF, Li JF et al (2020) Intestinal flora as a potential strategy to fight SARS-CoV-2 infection. Front Microbiol. https://doi.org/ 10.3389/fmicb.2020.01388

Herrmann J, Mori V, Bates JHT, Suki B (2020) Modeling lung perfusion abnormalities to explain early COVID-19 hypoxemia. Nat Commun. https://doi.org/10.1038/S41467-020-18672-6

Hoenigl M (2020) Invasive fungal disease complicating coronavirus disease 2019: when it rains, it spores. Clin Infect Dis. https://doi. org/10.1093/cid/ciaa1342

Honavar SG (2021) Code mucor: guidelines for the diagnosis, staging and management of rhino-orbito-cerebral mucormycosis in the setting of COVID-19. Indian J Ophthalmol 69:1361-1365. https://doi.org/10.4103/IJO.IJO_1165_21

Hu L, Zhou M, Young A et al (2019) In vivo effectiveness and safety of probiotics on prophylaxis and treatment of oral candidiasis: a systematic review and meta-analysis. BMC Oral Health 19:1-12. https://doi.org/10.1186/S12903-019-0841-2/TABLES/4

Hussain S, Baxi H, Riad A et al (2021) COVID-19-associated mucormycosis (CAM): an updated evidence mapping. Int J Environ Res Public Health. https://doi.org/10.3390/IJERPH181910340

Ibrahim AS, Spellberg B, Walsh TJ, Kontoyiannis DP (2012) Pathogenesis of mucormycosis. Clin Infect Dis 54:S16. https://doi.org/ 10.1093/cid/cir865

Ilavenil S, Park HS, Vijayakumar M et al (2015) Probiotic potential of lactobacillus strains with antifungal activity isolated from animal manure. Sci World J. https://doi.org/10.1155/2015/802570

Jeong W, Keighley C, Wolfe R et al (2019) The epidemiology and clinical manifestations of mucormycosis: a systematic review and meta-analysis of case reports. Clin Microbiol Infect 25:26-34. https://doi.org/10.1016/J.CMI.2018.07.011

John BV, Chamilos G, Kontoyiannis DP (2005) Hyperbaric oxygen as an adjunctive treatment for zygomycosis. Clin Microbiol Infect 11:515-517. https://doi.org/10.1111/j.1469-0691.2005.01170.x

John TM, Jacob CN, Kontoyiannis DP (2021) When uncontrolled diabetes mellitus and severe COVID-19 converge: the perfect storm for mucormycosis. J Fungi. https://doi.org/10.3390/JOF7040298

Karami S, Roayaei M, Zahedi E et al (2017) Antifungal effecats of Lactobacillus species isolated from local dairy products. Int J Pharm Investig 7:77. https://doi.org/10.4103/jphi.jphi_9_17

Kauffman CA (2019) Mucormycosis (zygomycosis)—UpToDate. In: UpToDate. https://www.uptodate.com/contents/mucormycos is-zygomycosis?search $=$ mucormycosis\&source $=$ search_resul t\&selectedTitle $=1 \sim 78 \&$ usage_type $=$ default\&display_rank $=1 \#$ H1. Accessed 17 Jun 2021

Kemna ME, Neri RC, Ali R, Salkin IF (1994) Cokeromyces recurvatus, a mucoraceous zygomycete rarely isolated in clinical laboratories. J Clin Microbiol 32:843-845

Kim H, Kang SS (2019) Antifungal activities against Candida albicans, of cell-free supernatants obtained from probiotic Pediococcus acidilactici HW01. Arch Oral Biol 99:113-119. https://doi. org/10.1016/j.archoralbio.2019.01.006

Kontoyiannis DP (2016) A potential explanation of a positive serum $\beta$-glucan assay in mucormycosis. Open Forum Infect Dis. https:// doi.org/10.1093/ofid/ofw209

Kontoyiannis DP, Lewis RE (2011) How I treat mucormycosis. Blood 118:1216-1224. https://doi.org/10.1182/blood-2011-03-316430

Kontoyiannis DP, Chamilos G, Hassan SA et al (2007) Increased culture recovery of zygomycetes under physiologic temperature conditions. Am J Clin Pathol 127:208-212. https://doi.org/10. 1309/7KU5XWURYM0151YN

Koshy S, Ismail N, Astudillo CL et al (2017) Breath-based diagnosis of invasive mucormycosis (IM). Open Forum Infect Dis 4:S53-S54. https://doi.org/10.1093/ofid/ofx162.124 
Kurrey NK, Anu-Appaiah KA, Rao RP (2019) Probiotic yeasts inhibit virulence of non-albicans candida species lohith kunyeit, a, b, c. Mbio. https://doi.org/10.1128/mBio.02307-19

Kyvernitakis A, Torres HA, Jiang Y et al (2016) Initial use of combination treatment does not impact survival of 106 patients with haematologic malignancies and mucormycosis: a propensity score analysis. Clin Microbiol Infect 22:811.e1-811.e8. https://doi.org/ 10.1016/J.CMI.2016.03.029

Lackner M, Caramalho R, Lass-Flörl C (2014) Laboratory diagnosis of mucormycosis: current status and future perspectives. Future Microbiol 9:683-695

Lancet T (2021) India's COVID-19 emergency. Lancet 397:1683

Lass-Flörl C, Mayr A (2009) Diagnosing invasive fungal diseaseslimitations of microbiological diagnostic methods. Expert Opin Med Diagn 3:461-470

Lau AF, Walchak RC, Miller HB et al (2019) Multicenter study demonstrates standardization requirements for mold identification by MALDI-TOF MS. Front Microbiol 10:2098. https://doi.org/10. 3389/fmicb.2019.02098

Layios N, Canivet JL, Baron F et al (2014) Mortierella wolfii-associated invasive disease. Emerg Infect Dis 20:1591-1592. https:// doi.org/10.3201/eid2009.140469

Lecointe K, Cornu M, Leroy J et al (2019) Polysaccharides cell wall architecture of Mucorales. Front Microbiol 10:469

Lewis RE, Albert ND, Liao G et al (2010) Comparative pharmacodynamics of amphotericin B lipid complex and liposomal amphotericin B in a murine model of pulmonary mucormycosis. Antimicrobal Agents Chemother 54:1298-1304. https://doi.org/10. 1128/AAC.01222-09

Lipińska L, Klewicki R, Klewicka E et al (2016) Antifungal activity of Lactobacillus sp. Bacteria in the presence of xylitol and galactosyl-xylitol. Biomed Res Int. https://doi.org/10.1155/2016/ 5897486

Liu Y, Wu H, Huang F et al (2013) Utility of 18F-FDG PET/CT in diagnosis and management of mucormycosis. Clin Nucl Med. https://doi.org/10.1097/rlu.0b013e3182867d13

Liu Y-C, Zhou M-L, Cheng K-J et al (2019) Successful treatment of invasive fungal rhinosinusitis caused by Cunninghamella: a case report and review of the literature. World J Clin Cases. https:// doi.org/10.12998/wjcc.v7.i2.228

Liu ET, Sun TT, Dong HJ et al (2020) Combined PET/CT with thoracic contrast-enhanced CT in assessment of primary cardiac tumors in adult patients. EJNMMI Res 10:1-13. https://doi.org/10.1186/ S13550-020-00661-X/FIGURES/7

Lumyongsatien M, Jaru-ampornpan P, Uiprasertkul M, Selva D (2020) Orbital Infection by Saksenaea vasiformis in an Immunocompetent Host. Case Rep Ophthalmol Med 2020:1-4. https://doi.org/ $10.1155 / 2020 / 8827074$

Machouart M, Larché J, Burton K et al (2006) Genetic identification of the main opportunistic Mucorales by PCR-restriction fragment length polymorphism. J Clin Microbiol 44:805-810. https://doi. org/10.1128/JCM.44.3.805-810.2006

Mahalaxmi I, Jayaramayya K, Venkatesan D et al (2021) Mucormycosis: an opportunistic pathogen during COVID-19. Environ Res 201:111643. https://doi.org/10.1016/J.ENVRES.2021.111643

Mahalmani V, Sarma P, Prakash A, Medhi B (2021) Role of iron chelators in mucormycosis. Indian J Pharmacol 53:261. https://doi. org/10.4103/IJP.IJP_604_21

Mallapaty S (2021) India's massive COVID surge puzzles scientists. Nature 592:667-668. https://doi.org/10.1038/ D41586-021-01059-Y

Mastroianni A (2004) Paranasal sinus mucormycosis in an immunocompetent host: Efficacy and safety of combination therapy with liposomal amphotericin B and adjuvant rHuGM-CSF. In: Infez. Med. https://pubmed.ncbi.nlm.nih.gov/15729020/. Accessed 10 Nov 2021
Mathieu D, Wattel F (2006) Physiologic effects of hyperbaric oxygen on microorganisms and host defences against infection. Handb Hyperb Med. https://doi.org/10.1007/1-4020-4448-8_7

Matsubara VH, Bandara HMHN, Mayer MPA, Samaranayake LP (2016) Probiotics as antifungals in mucosal candidiasis. Clin Infect Dis 62:1143-1153. https://doi.org/10.1093/CID/CIW038

Mohammadi F, Badri M, Safari S, Hemmat N (2021) A case report of rhino-facial mucormycosis in a non-diabetic patient with COVID-19: a systematic review of literature and current update. BMC Infect Dis 21:1-7. https://doi.org/10.1186/ S12879-021-06625-3/TABLES/2

Morace G, Borghi E (2012) Invasive mold infections: virulence and pathogenesis of Mucorales. Int J Microbiol. https://doi.org/10. $1155 / 2012 / 349278$

Morais AHA, Passos TS, Maciel BLL, da Silva-Maia JK (2020) Can probiotics and diet promote beneficial immune modulation and purine control in coronavirus infection? Nutrients 12:1-18. https://doi.org/10.3390/nu12061737

Mylonakis E, Clancy CJ, Ostrosky-Zeichner L et al (2015) T2 magnetic resonance assay for the rapid diagnosis of candidemia in whole blood: a clinical trial. Clin Infect Dis 60:892-899. https://doi.org/10.1093/cid/ciu959

Neblett Fanfair R, Benedict K, Bos J et al (2012) Necrotizing cutaneous mucormycosis after a tornado in Joplin, Missouri, in 2011. N Engl J Med 367:2214-2225. https://doi.org/10.1056/ nejmoa1204781

Odronic SI, Scheidemantel T, Tuohy MJ et al (2012) Two cases of cokeromyces recurvatus in liquid-based papanicolaou tests and a review of the literature. Archives of pathology and laboratory medicine. Allen Press, pp 1593-1596

Olaimat AN, Aolymat I, Al-Holy M et al (2020) The potential application of probiotics and prebiotics for the prevention and treatment of COVID-19. Npj Sci Food. https://doi.org/10.1038/ s41538-020-00078-9

Orne C, Burnham-marusich A, Baldin C, et al (2018) Cell wall fucomannan is a biomarker for diagnosis of invasive murine mucormycosis

Pandey SK, Sharma V (2018) World diabetes day 2018: battling the emerging epidemic of diabetic retinopathy. Indian J Ophthalmol 66:1652. https://doi.org/10.4103/IJO.IJO_1681_18

Patel A, Agarwal R, Rudramurthy SM et al (2021) Early releasemulticenter epidemiologic study of coronavirus disease-associated mucormycosis, India—volume 27, number 9-September 2021 - emerging infectious diseases journal-CDC. Emerg Infect Dis. https://doi.org/10.3201/EID2709.210934

Patrick CC, Cohen-Abbo A, Bozeman PM (1993) Cunninghamella infections: review and report of two cases of Cunninghamella pneumonia in immunocompromised children. Clin Infect Dis 17:173-177. https://doi.org/10.1093/clinids/17.2.173

Peng J, Zhang M, Yao G et al (2021) Probiotics as adjunctive treatment for patients contracted COVID-19: current understanding and future needs. Front Nutr 8:304. https://doi.org/10.3389/ FNUT.2021.669808/BIBTEX

Perricone C, Bartoloni E, Bursi R et al (2020) COVID-19 as part of the hyperferritinemic syndromes: the role of iron depletion therapy. Immunol Res 68:213-224. https://doi.org/10.1007/ S12026-020-09145-5/FIGURES/1

Petrikkos G, Tsioutis C (2018) Recent advances in the pathogenesis of mucormycoses. Clin Ther 40:894-902

Petrikkos G, Skiada A, Lortholary O et al (2012) Epidemiology and clinical manifestations of mucormycosis. Clin Infect Dis 54:S23-S34. https://doi.org/10.1093/cid/cir866

Pilch WT, Kinnear N, Hennessey DB (2017) Saksenaea vasiformis infection in an immunocompetent patient in rural Australia. BMJ Case Rep. https://doi.org/10.1136/bcr-2017-220341

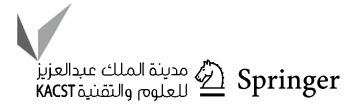


Potenza L, Vallerini D, Barozzi P et al (2011) Mucorales-specific T cells emerge in the course of invasive mucormycosis and may be used as a surrogate diagnostic marker in high-risk patients. Blood 118:5416-5419. https://doi.org/10.1182/blood-2011-07-366526

Prakash H, Chakrabarti A (2021) Epidemiology of mucormycosis in India. Microorganisms 9:1-12

Rahman A, Tabassum T, Araf Y et al (2021) Silent hypoxia in COVID19: pathomechanism and possible management strategy. Mol Biol Rep 48:1. https://doi.org/10.1007/S11033-021-06358-1

Rashid S, Ben Abid F, Babu S et al (2021) Fatal renal mucormycosis with Apophysomyces elegans in an apparently healthy male. Aging Male 23:746-749. https://doi.org/10.1080/13685538. 2019.1586871

Raut A, Huy NT (2021) Rising incidence of mucormycosis in patients with COVID-19: another challenge for India amidst the second wave? Lancet Respir Med. https://doi.org/10.1016/S22132600(21)00265-4

Rawson TM, Wilson RC, Holmes A (2021) Understanding the role of bacterial and fungal infection in COVID-19. Clin Microbiol Infect 27:9-11

Reed C, Bryant R, Ibrahim AS et al (2008) Combination polyenecaspofungin treatment of rhino-orbital-cerebral mucormycosis. Clin Infect Dis 47:364. https://doi.org/10.1086/589857

Reid G, Lynch JP, Fishbein MC, Clark NM (2020) Mucormycosis. Semin Respir Crit Care Med 41:099-114. https://doi.org/10. 1055/S-0039-3401992

Ribes JA, Vanover-Sams CL, Baker DJ (2000) Zygomycetes in human disease. Clin Microbiol Rev 13:236-301

Rickerts V, Böhme A, Viertel A et al (2000) Cluster of pulmonary infections caused by Cunninghamella bertholletiae in immunocompromised patients. Clin Infect Dis 31:910-913. https://doi. org/10.1086/318144

Rickerts V, Atta J, Herrmann S et al (2006) Successful treatment of disseminated mucormycosis with a combination of liposomal amphotericin B and posaconazole in a patient with acute myeloid leukaemia. Mycoses 49:27-30. https://doi.org/10.1111/j.14390507.2006.01299.x

Rippon JW, Dolan CT (1979) Colonization of the vagina by fungi of the genus Mucor. Clin Microbiol Newsl 1:4-5

Roilides E, Lyman CA, Panagopoulou P, Chanock S (2003) Immunomodulation of invasive fungal infections. Infect Dis Clin North Am 17:193-219. https://doi.org/10.1016/S0891-5520(02) 00070-3

Roilides E, Kontoyiannis DP, Walsh TJ (2012) Host defenses against zygomycetes. Clin Infect Dis 54:S61-S66. https://doi.org/10. 1093/CID/CIR869

Rossoni RD, de Barros PP, de Alvarenga JA et al (2018) Antifungal activity of clinical Lactobacillus strains against Candida albicans biofilms: identification of potential probiotic candidates to prevent oral candidiasis. Biofouling 34:212-225. https://doi.org/ 10.1080/08927014.2018.1425402

Russo P, Arena MP, Fiocco D et al (2017) Lactobacillus plantarum with broad antifungal activity: a promising approach to increase safety and shelf-life of cereal-based products. Int J Food Microbiol 247:48-54. https://doi.org/10.1016/j.ijfoodmicro.2016.04. 027

Saksena SB (1953) A new genus of the mucorales. Mycologia 45:426436. https://doi.org/10.1080/00275514.1953.12024280

Salari S, Ghasemi Nejad Almani P (2020) Antifungal effects of Lactobacillus acidophilus and Lactobacillus plantarum against different oral Candida species isolated from HIV/ AIDS patients: an in vitro study. J Oral Microbiol. https://doi.org/10.1080/20002 297.2020.1769386

Samson R, Navale GR, Dharne MS (2020) Biosensors: frontiers in rapid detection of COVID-19. 3 Biotech. https://doi.org/10.1007/ s13205-020-02369-0
Scalise A, Barchiesi F, Viviani MA et al (1999) Infection due to Absidia corymbifera in a patient with a massive crush trauma of the foot. J Infect 38:191-192. https://doi.org/10.1016/ S0163-4453(99)90250-5

Scherer E, Iriart X, Bellanger AP et al (2018) Quantitative PCR (qPCR) detection of mucorales DNA in bronchoalveolar lavage fluid to diagnose pulmonary mucormycosis. J Clin Microbiol. https://doi.org/10.1128/JCM.00289-18

Schlebusch S, Looke DFM (2005) Intraabdominal zygomycosis caused by Syncephalastrum racemosum infection successfully treated with partial surgical debridement and high-dose amphotericin B lipid complex. J Clin Microbiol 43:5825-5827. https://doi.org/10.1128/JCM.43.11.5825-5827.2005

Schmidt S, Tramsen L, Perkhofer S et al (2013) Rhizopus oryzae hyphae are damaged by human natural killer (NK) cells, but suppress NK cell mediated immunity. Immunobiology 218:939-944. https://doi.org/10.1016/J.IMBIO.2012.10.013

Schmidt S, Schneider A, Demir A et al (2016) Natural killer cellmediated damage of clinical isolates of mucormycetes. Mycoses 59:34-38. https://doi.org/10.1111/MYC.12431

Scott C, Arora G, Dickson K, Lehmann C (2021) Iron chelation in local infection. Molecules. https://doi.org/10.3390/molecules2 6010189

Segrelles-Calvo G, De Saraújo GR, Frases S (2020) Systemic mycoses: a potential alert for complications in COVID-19 patients. Future Microbiol 15:1405-1413

Severo LC, Job F, Mattos TC (1991) Systemic zygomycosis: nosocomial infection by Rhizomucor pusillus. Mycopathologia 113:79-80. https://doi.org/10.1007/BF00442413

Shoenfeld Y (2020) Corona (COVID-19) time musings: Our involvement in COVID-19 pathogenesis, diagnosis, treatment and vaccine planning. Autoimmun Rev 19:102538. https://doi.org/10. 1016/J.AUTREV.2020.102538

Siddiqui A, Davidson JD, Mustoe TA (1997) Ischemic tissue oxygen capacitance after hyperbaric oxygen therapy: a new physiologic concept. Plast Reconstr Surg 99:148-155. https://doi. org/10.1097/00006534-199701000-00023

Silva MP, Rossoni RD, CamposJunqueira J, Jorge AOC (2016) Probiotics for prevention and treatment of candidiasis and other infectious diseases: Lactobacillus spp. and other potential bacterial species. Probiotics Prebiotics Hum Nutr Heal. https://doi. org/10.5772/64093

Singh AK, Singh R, Joshi SR, Misra A (2021) Mucormycosis in COVID-19: a systematic review of cases reported worldwide and in India. Diabetes Metab Syndr Clin Res Rev. https://doi. org/10.1016/j.dsx.2021.05.019

Skiada A, Lass-Floerl C, Klimko N et al (2018) Challenges in the diagnosis and treatment of mucormycosis. Med Mycol 56:S93-S101

Skiada A, Lanternier F, Groll AH, et al (2013) Diagnosis and treatment of mucormycosis in patients with hematological malignancies: guidelines from the 3rd European Conference on Infections in Leukemia (ECIL 3). Haematologica. 98:492-504. https://doi.org/ 10.3324/HAEMATOL.2012.065110

Song B-I (2019) F-18 fluorodeoxyglucose positron emission tomography/computed tomography image of gastric mucormycosis mimicking advanced gastric cancer: a case report. World J Clin Cases 7:1155-1160. https://doi.org/10.12998/wjcc.v7.i10.1155

Song G, Liang G, Liu W (2020) Fungal co-infections associated with global COVID-19 pandemic: a clinical and diagnostic perspective from China. Mycopathologia 185:599-606

Sonnweber T, Boehm A, Sahanic S et al (2020) Persisting alterations of iron homeostasis in COVID-19 are associated with non-resolving lung pathologies and poor patients' performance: a prospective observational cohort study. Respir Res 21:1-9. https://doi.org/ 10.1186/S12931-020-01546-2/FIGURES/4 
Spanu T, Posteraro B, Fiori B et al (2012) Direct MALDI-TOF mass spectrometry assay of blood culture broths for rapid identification of Candida species causing bloodstream infections: an observational study in two large microbiology laboratories. J Clin Microbiol 50:176-179. https://doi.org/10.1128/JCM.05742-11

Spellberg B, Edwards J, Ibrahim A (2005) Novel perspectives on mucormycosis: pathophysiology, presentation, and management. Clin Microbiol Rev 18:556-569

Spellberg B, Walsh TJ, Kontoyiannis DP et al (2009) Recent advances in the management of mucormycosis: from bench to bedside. Clin Infect Dis 48:1743. https://doi.org/10.1086/599105

Spellberg B, Maertens J (1991) Principles and Practice of Infectious Diseases. In: Ann Intern Med https://books.google.co.in/books? $\mathrm{id}=\mathrm{IGydDwAAQBAJ} \& \mathrm{pg}=\mathrm{PA} 582 \& \mathrm{lpg}=\mathrm{PA} 582 \& \mathrm{dq}=\mathrm{It}+\mathrm{is}+$ critical+to+reverse+or+prevent+underlying+defects+in+ host+defense+when+treating+patients+with+mucormycosis . \&source=bl\&ots $=1$ yehkILRJ9\&sig $=$ ACfU3U25rcvJChVrXtzY rpXoEFwmJZBn2w\&hl=en\&. Accessed 11 Nov 2021

St-Germain G, Robert A, Ishak M et al (1993) Infection due to Rhizomucor pusillus: report of four cases in patients with leukemia and review. Clin Infect Dis 16:640-645. https://doi.org/10.1093/ clind/16.5.640

Symeonidis AS (2009) The role of iron and iron chelators in zygomycosis. Clin Microbiol Infect 15:26-32

Tang H, Bohannon L, Lew M et al (2021) Randomised, double-blind, placebo-controlled trial of probiotics to eliminate COVID-19 transmission in exposed household contacts (PROTECT-EHC): a clinical trial protocol. BMJ Open. https://doi.org/10.1136/ BMJOPEN-2020-047069

Therese KL, Lakshmipathy M, Lakshmipathy D (2020) First report of Mortierella wolfii causing fungal keratitis from a tertiary eye hospital in India. Indian J Ophthalmol 68:2272-2274. https://doi. org/10.4103/ijo.IJO_2136_19

Tolle LB, Standiford TJ (2013) Danger-associated molecular patterns (DAMPs) in acute lung injury. J Pathol 229:145-156

Tragiannidis A, Groll AH (2009) Hyperbaric oxygen therapy and other adjunctive treatments for zygomycosis. Clin Microbiol Infect 15:82-86. https://doi.org/10.1111/J.1469-0691.2009.02986.X

Tsai TW, Hammond LA, Rinaldi M et al (1997) Cokeromyces recurvatus infection in a bone marrow transplant recipient. Bone Marrow Transplant 19:301-302. https://doi.org/10.1038/sj.bmt.1700647

Valente Aguiar PD, Carvalho B, Monteiro P et al (2021) Hyperbaric oxygen treatment: results in seven patients with severe bacterial postoperative central nervous system infections and refractory mucormycosis. Diving Hyperb Med. https://doi.org/10.28920/ dhm51.1.86-93

Vargas-Vargas M, Cortés-Rojo C (2020) Ferritin levels and COVID19. Rev Panam Salud Publica. https://doi.org/10.26633/RPSP. 2020.72

Vicariotto F, Del Piano M, Mogna L, Mogna G (2012) Effectiveness of the association of 2 probiotic strains formulated in a slow release vaginal product, in women affected by vulvovaginal candidiasis: a pilot study. J Clin Gastroenterol. https://doi.org/10.1097/MCG. 0B013E3182684D71

Voigt K, Cigelnik E, O’Donnell K (1999) Phylogeny and PCR identification of clinically important zygomycetes based on nuclear
ribosomal-DNA sequence data. J Clin Microbiol 37:3957-3964. https://doi.org/10.1128/jcm.37.12.3957-3964.1999

Walsh TJ, Finberg RW, Arndt C et al (2008) Liposomal amphotericin $\mathrm{B}$ for empirical therapy in patients with persistent fever and neutropenia. N Engl J Med. https://doi.org/10.1056/NEJM199903 113401004

Walsh TJ, Gamaletsou MN, McGinnis MR et al (2012) Early clinical and laboratory diagnosis of invasive pulmonary, extrapulmonary, and disseminated mucormycosis (zygomycosis). Clin Infect Dis 54:S55-S60. https://doi.org/10.1093/cid/cir868

Walther G, Wagner L, Kurzai O (2019) Updates on the taxonomy of mucorales with an emphasis on clinically important taxa. J Fungi 5:106

DH Webdesk (2021) Covid-19 crisis: Which states in India have reported the highest number of mucormycosis cases? I Deccan Herald

Weitzman I, Whittier S, McKitrick JC, Della-Latta P (1995) Zygospores: the last word in identification of rare or atypical zygomycetes isolated from clinical specimens. J Clin Microbiol 33:781-783

Wickline CL, Cornitius TG, Butler T (1989) Cellulitis caused by rhizomucor pusillus in a diabetic patient receiving continuous insulin infusion pump therapy. South Med J 82:1432-1434. https:// doi.org/10.1097/00007611-198911000-00024

Wu Z, Tsumura Y, Blomquist G, Wang XR (2003) 18S rRNA gene variation among common airborne fungi, and development of specific oligonucleotide probes for the detection of fungal isolates. Appl Environ Microbiol 69:5389-5397. https://doi.org/10. 1128/AEM.69.9.5389-5397.2003

Wysong DR, Waldorf AR (1987) Electrophoretic and immunoblot analyses of Rhizopus arrhizus antigens. J Clin Microbiol 25:358-363. https://doi.org/10.1128/jcm.25.2.358-363.1987

Yan Y, He Y, Maier T et al (2011) Improved identification of yeast species directly from positive blood culture media by combining sepsityper specimen processing and microflex analysis with the matrix-assisted laser desorption ionization biotyper system. J Clin Microbiol 49:2528-2532. https://doi.org/10.1128/JCM. 00339-11

Yasmin F, Najeeb H, Naeem A et al (2021) COVID-19 associated mucormycosis: a systematic review from diagnostic challenges to management. Diseases. https://doi.org/10.3390/DISEASES90 40065

Yépez A, Luz C, Meca G et al (2017) Biopreservation potential of lactic acid bacteria from Andean fermented food of vegetal origin. Food Control 78:393-400. https://doi.org/10.1016/j.foodc ont.2017.03.009

Zacharioudakis IM, Zervou FN, Mylonakis E (2018) T2 magnetic resonance assay: overview of available data and clinical implications. J Fungi 4:45

Zeilender S, Drenning D, Glauser FL, Bechard D (1990) Fatal Cunninghamella bertholletiae infection in an immunocompetent patient. Chest 97:1482-1483. https://doi.org/10.1378/chest. 97.6.1482 